\title{
An enhanced individual placement and support (IPS) intervention based on the Model of Human Occupation (MOHO); a prospective cohort study
}

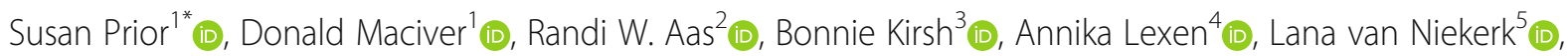
Linda Irvine Fitzpatrick ${ }^{6}$ and Kirsty Forsyth ${ }^{1}$ (D)

\begin{abstract}
Background: Employment is good for physical and mental health, however people with severe mental illness (SMI) are often excluded from employment. Standard Individual Placement and Support (IPS) is effective in supporting around 55\% of people with SMI into employment or education. Current research considers enhancements to IPS to improve outcomes for those requiring more complex interventions. Clinicians need to better understand who will benefit from these enhanced IPS interventions. This study offers a new enhanced IPS intervention and an approach to predicting who may achieve successful outcomes.
\end{abstract}

Methods: This prospective cohort study included people with SMI who participated in an enhanced IPS service and had prolonged absence from employment. Secondary data analysis was conducted of data gathered in routine clinical practice. Univariate analysis coupled with previous research and clinical consultation was used to select variables to be included in the initial model, followed by a backward stepwise approach to model building for the final multiple logistic regression model with an outcome of successful or unsuccessful goal attainment (employment or education).

Results: Sixty-three percent of participants in the enhanced IPS successfully attained employment or education. Significant relationships from bivariate analyses were identified between outcomes (employment or education) and seven psychosocial variables. Adapting Routines to Minimise Difficulties, Work Related Goals, and Living in an Area of Lesser Deprivation were found to be significant in predicting employment or education in the final multiple logistic regression model $R^{2}=0.16$ (Hosmer-Lemeshow), 0.19 (Cox-Snell), 0.26 (Nagelkerke). Model $\chi^{2}(7)=41.38 p<.001$.

Conclusion: An enhanced IPS service had a 63\% rate success in achieving employment or education, higher than comparable studies and provides an alternative to IPS-Lite and IPS-standard for more complex populations. Motivational and habitual psychosocial variables are helpful in predicting who may benefit from an enhanced IPS intervention supporting people after prolonged absence from employment.

Trial registration: NCT04083404 Registered 05 September 2019 (retrospectively registered).

Keywords: Severe mental illness, Employment, Enhanced Individual Placement \& Support, Model of human occupation

\footnotetext{
* Correspondence: sprior@qmu.ac.uk

${ }^{1}$ Queen Margaret University, Edinburgh EH21 6UU, UK

Full list of author information is available at the end of the article
}

C C The Author(s). 2020 Open Access This article is licensed under a Creative Commons Attribution 4.0 International License, which permits use, sharing, adaptation, distribution and reproduction in any medium or format, as long as you give appropriate credit to the original author(s) and the source, provide a link to the Creative Commons licence, and indicate if changes were made. The images or other third party material in this article are included in the article's Creative Commons. licence, unless indicated otherwise in a credit line to the material. If material is not included in the article's Creative Commons licence and your intended use is not permitted by statutory regulation or exceeds the permitted use, you will need to obtain permission directly from the copyright holder. To view a copy of this licence, visit http://creativecommons.org/licenses/by/4.0/. The Creative Commons Public Domain Dedication waiver (http://creativecommons.org/publicdomain/zero/1.0/) applies to the data made available in this article, unless otherwise stated in a credit line to the data. 


\section{Background}

Everyone is entitled to work and fair renumeration [1] . Work is highly valued by society, offering the opportunity for self-identity and improved financial and social status [2]. However, people with severe mental illness (SMI) are often excluded from this human right $[3,4]$. Standard Individual Placement and Support (IPS) (Table 1) has been identified as the most effective vocational rehabilitation intervention, with $55 \%$ of people with SMI successfully attain employment [5]. Metaanalytic studies confirm that standard IPS is superior to all non IPS interventions [6-9]. However, while effective for more than half of participants, $45 \%$ of those accessing Standard IPS do not attain their employment or education goals. Hence, recent investigations have focused on enhancements to improve outcomes for those requiring more complex interventions, to date these have primarily focused on interventions to improve cognitive and social skills [10-15]. Developing enhanced IPS and to be able to predict who secures employment or education has therefore become a priority for practice and research $[11,16,17]$.

Studies examining predictors of success have identified that demographic factors alone are not sufficient to predict attainment of employment goals for people with SMI $[18,19]$. Clinical presentation cannot predict outcomes [20] with negative symptoms associated with unemployment $[21,22]$. Some studies have found active, positive symptoms are associated with failure to attain employment [22, 23] or loss of employment [24]; while others, including a meta-analysis [15], have found no association. Psychosocial variables such as a strong work ethic [25-27], expressed desire to work [28-30], maintain habits $[19,31]$ and self-esteem, self-efficacy [19, 32-

Table 1 Principles of Standard Individual Placement and Support \& Enhanced Individual Placement and Support

Principles of Standard Individual Placement and Support (Bond et al. 2011)

1. Eligibility is based on consumer choice

2. Competitive employment is the goal

3. Supported employment is integrated with treatment

4. Personalized benefits planning is provided

5. Rapid job search is encouraged

6. Employment specialists build employer relationships

7. Follow-along supports are continuous

8. Consumer preferences are important

Additional Principals for Enhanced Individual Placement and Support

9. Delivered by Occupational Therapists

10. Underpinned by the Model of Human Occupation

11. Use of Worker Role Interview at start of program

12. Focus on integrating daily life with working life
$34]$ and work history [15, 35] have also been investigated and identified as predictive of success in return to employment or education.

Given the predictive nature of psychosocial variables, an enhanced IPS program (Table 1) was constructed using theoretical principles of the model of human occupation (MOHO) [36]. These include psychosocial concepts related to values and attitudes; habits and routines; performance and environment context (Table 2). The relevance of the $\mathrm{MOHO}$ to understanding psychosocial factors predicting return to employment from sickness absence has been established [37, 38]. A similar approach is considered appropriate for a SMI population who are unemployed and seeking employment or education [17].

This study, therefore, investigates an enhanced IPS service for people with SMI who are unemployed and seeking employment or education. It seeks to explore if theoretically derived psychosocial variables can predict employment or education outcomes in this population. While recognising the lack of consensus in defining an SMI population $[39,40]$ this study has adopted the definition used in IPS meta-analysis (diagnosis is predominantly psychotic disorders; disorder is persistent over time and difficulties in functioning in one or more areas of daily life) [9].

\section{Method \\ Design}

A prospective cohort study [41] was undertaken, which utilised a secondary dataset [42] . The dataset was provided by an established vocational rehabilitation service, experienced in providing a standard IPS intervention [43] with a good fidelity rating to the established IPS principles. The service simultaneously delivers a theoretically enhanced IPS service delivered by occupational therapists underpinned by the Model of Human Occupation. The study is a secondary analysis of data collected for clinical purposes. The dataset was designed in collaboration with the academic team at the inception of this service, thus ensuring that the measurement tools and data would be appropriate to research purposes [44, 45]. Data was anonymised within the clinical service and transferred using a secure email transfer. Procedures for anonymisation and transfer of data were detailed in the ethical application approved by the proportionate review sub-committee of the South Central - Berkshire B Research Ethics Committee (IRAS ID 230949).

\section{Measures}

Clinicians use an assessment called the Worker Role Interview (WRI) [46] to identify psychosocial issues at entry into the service (Table 2) which guides the team's interventions (Table 1). The WRI identifies psychosocial 
Table 2 Theoretically defined psychosocial variables (derived from WRI)

\begin{tabular}{|c|c|c|c|}
\hline $\begin{array}{l}\text { Psychosocial } \\
\text { areas }\end{array}$ & $\begin{array}{l}\text { Theoretical Concept } \\
\text { From Moho }\end{array}$ & $\begin{array}{l}\text { Variable Derived From } \\
\text { Theory }\end{array}$ & Definition of variable \\
\hline \multirow[t]{7}{*}{$\begin{array}{l}\text { Motivational } \\
\text { variables }\end{array}$} & \multirow[t]{3}{*}{ Personal Causation } & $\begin{array}{l}\text { Assesses abilities and } \\
\text { Limitations; }\end{array}$ & $\begin{array}{l}\text { Individual's capacity to accurately assess his/her abilities and what they mean for } \\
\text { work performance. }\end{array}$ \\
\hline & & $\begin{array}{l}\text { Expectation of job } \\
\text { success; }\end{array}$ & A client's belief that he/she will be able to work. \\
\hline & & Takes responsibility; & $\begin{array}{l}\text { How much responsibility a client takes for his/her work actions and their } \\
\text { consequences. }\end{array}$ \\
\hline & \multirow[t]{2}{*}{ Values } & Commitment to work; & The client's commitment to work and importance placed on work. \\
\hline & & Work-related goals; & Ability to set and attain goals at his/her work setting or for finding work \\
\hline & \multirow[t]{2}{*}{ Interests } & Enjoys work; & Pleasure or enjoyment client finds within work. \\
\hline & & Pursues interests; & $\begin{array}{l}\text { The ability of an individual to assess own interests and find ways to use these } \\
\text { skills in } \& / \text { outside of the work situation. }\end{array}$ \\
\hline \multirow[t]{5}{*}{$\begin{array}{l}\text { Habitual } \\
\text { variables }\end{array}$} & \multirow[t]{2}{*}{ Roles } & $\begin{array}{l}\text { Appraises work } \\
\text { expectations; }\end{array}$ & Client's ability to internalize both general and specific expectations of work. \\
\hline & & Influence of other roles; & How much other roles in the client's life influence his/her return to work \\
\hline & \multirow[t]{3}{*}{ Habits } & Work Habits; & Degree of organization and routine in work. \\
\hline & & Daily Routine; & Degree of organization and routine outside of work. \\
\hline & & $\begin{array}{l}\text { Adapts routines to } \\
\text { minimize difficulties; }\end{array}$ & $\begin{array}{l}\text { How the person has managed use of time, routine, and habits since the injury or } \\
\text { since being out of work. }\end{array}$ \\
\hline \multirow[t]{4}{*}{ Skills } & \multirow[t]{4}{*}{ Performance Capacity } & Motor Skills & Moving body or objects in work environment \\
\hline & & Process Skills & Logically sequencing actions; selecting \& using appropriate materials/tools; \\
\hline & & Interaction and & \\
\hline & & Communication Skills & $\begin{array}{l}\text { Ability to convey intentions and needs; express self to allow for involvement and } \\
\text { co-ordinated social action }\end{array}$ \\
\hline \multirow[t]{5}{*}{ Environment } & \multirow[t]{5}{*}{ Environment } & \multirow{2}{*}{$\begin{array}{l}\text { Perception of physical } \\
\text { work setting; }\end{array}$} & The physical environment in which the client works, or hopes to work in. \\
\hline & & & Family's and peers' influence on the client's ability to return to previous work. \\
\hline & & $\begin{array}{l}\text { Perception of family and } \\
\text { peers; }\end{array}$ & $\begin{array}{l}\text { Influence of boss and/or company on the ability of client to return to previous } \\
\text { work / find \& keep work. }\end{array}$ \\
\hline & & $\begin{array}{l}\text { Perception of boss and/or } \\
\text { company; }\end{array}$ & $\begin{array}{l}\text { Co-workers' influence on client's ability to return to previous work and find and } \\
\text { keep work. }\end{array}$ \\
\hline & & Perception of co-workers & \\
\hline
\end{tabular}

and environmental factors that influence a client's ability to find a job, remain in work, or return to work after injury or disease $[36,46]$. The WRI has a sound theoretically base, the Model of Human Occupation (MOHO) [36]. The WRI consists of a semi-structured interview, a standardised four-point rating scale is then completed by therapists. Items are summarised in Table 2 (fuller definitions are provided at clinical trials repository (NCT04083404)). The rating scale measures the impact of items on the client's work ability [46]. The reliability and validity of the WRI has been established internationally and across populations, including SMI [47-50]. This study collapsed the 4 point WRI scale into a binary rating i.e., supports $(4=$ strongly supports and $3=$ supports) and interferes ( 2 = interferes and $1=$ strongly interferes). Socioeconomic status was measured by Scottish Indices of Multiple Deprivation (SIMD) which provides a relative measure of deprivation by postcode. SIMD measures: current income; employment; health; education; skills and training; housing; geographic access and crime. The Scottish Government take a national approach to calculating and weighting domains into small postcode areas, called 'data zones', with roughly equal population. Least deprived areas were defined as quintile 5 and more deprived areas defined as quintiles 1-4. The previous employment variable was defined as being inclusive of any work experience from teenage life to present day.

\section{Sample}

The following inclusion criteria were applied: people with SMI, age 18 or above; consented to enhanced IPS intervention; had a goal of securing paid employment or education; had mutually agreed ongoing intervention or discharge from service prior to successful outcome. 
Exclusion criteria comprised: no employment/education goal; already in employment; refused engagement; withdrew from intervention. Based on the guideline of a minimum of 10 events per predictor variable [51], a sample size of 202 would allow for the robust estimation of 8 variables in the model.

\section{Analysis}

All analysis was conducted in $\mathrm{R}$ data analysis software [52]. The outcome variable of interest to this study identifies those who 'did attain' and 'did not attain' their goal of employment or education programme. Logistic regression, which can handle dichotomous outcomes was therefore used in the analysis. Key assumptions of logistic regression were tested: independence of errors, linearity of relationship between continuous predictor variables and log-transformed outcome, absence of multicollinearity between predictor variables. A backward stepwise approach was adopted to building logistic regression models [53]. It is recommended that variable selection should be guided by well-established theory, clinical observations, and preliminary analysis [53]. An initial step in this study for selecting variables included bivariate analyses for determining relationships between each independent variable and the outcome. A $p$-value cut-off of 0.06 was used to guide inclusion of variables in the initial logistic model as exclusion of important variables is possible with rigid application of traditional levels (0.05) [54]. Pearson's chi-squared test of independence using Yates correction was conducted to determine the association between categorical predictors (demographic or psychosocial) and outcome variable (obtained / did not obtain employment or education), while unpaired $t$ tests were used to compare the difference in means of continuous predictors across the two levels of the outcome. Variables showing statistically significant associations or differences from bivariate analyses were then reviewed by clinical consultation, leading to the inclusion of seven variables in the initial logistic model. Finally, multiple logistic regression was conducted utilizing the glm function in the $\mathrm{R}$ stats package. The goodness of fit of models was tested using the asymptotically chi-square distributed residual deviance and pseudo $R^{2}$. The deviance statistic along with its degrees of freedom and associated $p$-value, and three versions of $\mathrm{R}^{2}$ as recommended [55] are reported: the Hosmer and Lemshow $R^{2}$, based on the chi-square score; Cox and Snells' $R^{2}$, based on the deviance of the model: and finally as Cox and Snells' statistic never reaches a theoretical maximum of 1 , Nagelkerke's $R^{2}$ provides a correction. Co-efficient estimates are reported (with standard error). Odds ratios estimating the likelihood of obtaining employment or education for different covariates are also presented. Nested models were compared using the likelihood ratio test computing a difference in deviance statistics. Final model diagnostics included checking for independence of errors, absence of multicollinearity, and lack of strongly influential outliers [53, $55,56]$. In general, models with fewer variables are simpler; and without evidence of a significant difference, the simpler model is preferred $[53,54]$.

\section{Results \\ Therapists}

The 21 occupational therapists who gathered data are described in Table 3, with details of their experience and numbers of cases submitted to the study. Nineteen percent did not complete certificated IPS training during their time with the service, but mentorship and supervision ensured an evidence-based approach was maintained in IPS and MOHO. IPS training was secured online through the originators of the model in the US (ipsworks.org), and more recently in the UK.

\section{Participants}

Referrals to the service between 2015 and 2018 were screened, this included 353 people. A total of 202 people met the inclusion criteria. Their demographic characteristics are summarised in Table 4. Reasons for exclusion from the study were: 48 did not have employment/education goal; 6 were in employment; 72 withdrew (45 due to deterioration in health and 27 refused engagement); 10 moved address; 4 deceased; 3 unavailable data; 8 other reasons. The sample was predominately male $(61 \%)$ with a mean age 37.4 years (SD 10.80). Half of the sample (52\%) met the diagnostic category group of ICD10 F20-29 schizophrenia, schizotypal and delusional disorders [57]. A third met the diagnostic criteria for ICD10 F30-39 Mood (affective) disorders [57]: primarily bipolar affective disorder. The group is predominately well educated, with $60 \%$ having pursued education beyond high school level. A small proportion (9\%) did not attain any school-level qualifications. The majority (90\%) had had some experience of paid employment.

\section{Intervention}

The average duration of enhanced IPS intervention to positive outcome or to discharge was just over a year: 12.2 months (SD11.40). However duration of intervention is not normally distributed and the median duration is $8.4 \mathrm{mths}$ (IQ range 5.1-16.7). Positive outcomes of the enhanced IPS intervention were first attainment of employment or educational opportunity, 128 participants (63\%) had a positive outcome and 74 (37\%) were unsuccessful. 
Table 3 Therapists' Experience and Contribution of Data

\begin{tabular}{|c|c|c|c|c|}
\hline \multicolumn{3}{|c|}{ Level of experience (all competent in MOHO and IPS) } & \multicolumn{2}{|c|}{ Number of assessments included in datase } \\
\hline & $\mathrm{n}$ & $\%$ clinicians & $n$ & $\%$ dataset \\
\hline Novice (No IPS Certificate) & 4 & 19 & 11 & $5 \%$ \\
\hline Novice & 6 & 29 & 25 & $12 \%$ \\
\hline Experienced & 8 & 38 & 96 & $48 \%$ \\
\hline Expert & 3 & 14 & 70 & $35 \%$ \\
\hline
\end{tabular}

Table 4 Demographic Characteristics and summary of missing data

\begin{tabular}{|c|c|c|c|c|}
\hline \multicolumn{3}{|l|}{ Characteristic } & \multicolumn{2}{|c|}{ Missing data } \\
\hline \multirow[t]{3}{*}{$\overline{\text { Age }}$} & Mean & $S D$ & 0 & $0 \%$ \\
\hline & 37.4 & 10.8 & & \\
\hline & $\mathrm{n}$ & $\%$ & n & $\%$ \\
\hline Gender & & & 0 & $0 \%$ \\
\hline male & 124 & $61.4 \%$ & & \\
\hline female & 78 & $38.6 \%$ & & \\
\hline Ehnicity & & & 0 & $0 \%$ \\
\hline other ethnic group & 17 & $8.4 \%$ & & \\
\hline White & 185 & $91.6 \%$ & & \\
\hline Diagnosis & & & 0 & $0 \%$ \\
\hline ICD10 Schizophrenia, schizotypal and delusional disorders & 105 & $52.0 \%$ & & \\
\hline ICD10 Mood [affective] disorders & 67 & $33.2 \%$ & & \\
\hline ICD10 other diagnosis & 30 & $14.9 \%$ & & \\
\hline SIMD & & & 0 & $0 \%$ \\
\hline most deprived quintile 1 & 38 & $18.8 \%$ & & \\
\hline quintile 2 & 35 & $17.3 \%$ & & \\
\hline quintile 3 & 33 & $16.3 \%$ & & \\
\hline quintile 4 & 32 & $15.8 \%$ & & \\
\hline least deprived quintile 5 & 64 & $31.7 \%$ & & \\
\hline Marital status & & & 6 & $3.0 \%$ \\
\hline Married / de facto & 33 & $16.8 \%$ & & \\
\hline Single & 163 & $83.2 \%$ & & \\
\hline Living Situation & & & 4 & $2.0 \%$ \\
\hline With others & 97 & $49.0 \%$ & & \\
\hline Alone & 101 & $51.0 \%$ & & \\
\hline Qualification Attainment & & & 2 & $1.0 \%$ \\
\hline Did Not Attain School Quals & 18 & $9.0 \%$ & & \\
\hline Exams from School & 61 & $30.5 \%$ & & \\
\hline Further Education & 121 & $60.5 \%$ & & \\
\hline Previous Employment & & & 0 & $0.0 \%$ \\
\hline Previous employment & 182 & $90.1 \%$ & & \\
\hline No previous experience & 20 & $9.9 \%$ & & \\
\hline
\end{tabular}




\section{Bivariate analysis}

Bivariate analyses on the demographic variables are presented in Table 5 and the psychosocial variables are presented in Table 6 . The continuous variable age met the assumptions for unpaired t-test, and the assumptions regarding estimated distribution was confirmed for each categorical variable applying Yates correction when required.

Significant relationships were identified between employment or education and several psychosocial variables; Adapts Routines to Minimise Difficulties ( $p=$ 0.0001), Work Related Goals $(p=0.001)$, Appraises Work Expectations $(p=0.01)$, Work Habits $(p=0.01)$, Daily Routine $(p=0.01)$, Takes Responsibility $(p=0.01)$, Least Deprived area $(p=0.01)$, Commitment to Work $(p=0.02), \quad$ age $\quad(p=0.02) . \quad$ Borderline significant relationships were identified between Outcome and Educational Attainment $(p=0.05)$ and Assesses Abilities and Limitations $(p=0.06)$. Following clinical consultation, two variables i.e., Work Habits and Assesses Abilities and Limitations, were excluded from the initial logistic model. Both variables were considered challenging to rate in clinical practice for long term unemployed and, therefore, of limited clinical applicability in this population.

\section{Multiple logistic regression}

The exclusion of cases containing missing data in the covariates of interest resulted in an inclusion of 195 cases in the multiple logistic regression [58]. One hundred and twenty four (64\%) had a successful outcome and $71(36 \%)$ were unsuccessful. Multiple logistic

Table 5 Demographic Bivariate analysis

\begin{tabular}{|c|c|c|c|c|c|c|c|}
\hline \multirow[t]{2}{*}{ Characteristic } & \multicolumn{2}{|c|}{ Attained employment/education } & \multicolumn{2}{|c|}{ Did not attain employment/education } & \multicolumn{3}{|c|}{ Two Sample t-test } \\
\hline & $\mathrm{n}$ & $\%$ & $\mathrm{n}$ & $\%$ & $t$ & $\mathrm{df}$ & $p$ \\
\hline \multirow[t]{3}{*}{ Age } & & & & & -2.45 & 200 & 0.02 \\
\hline & $\mathrm{n}$ & $\%$ & $n$ & $\%$ & \multicolumn{3}{|c|}{$\begin{array}{l}\text { Pearson's Chi-square test } \\
\text { (*with Yates Correction) }\end{array}$} \\
\hline & & & & & $\overline{x^{2}}$ & $\mathrm{df}$ & $p$ \\
\hline \multicolumn{8}{|l|}{ Gender } \\
\hline Male & 81 & $40.1 \%$ & 43 & $21.3 \%$ & $0.33^{*}$ & 1 & 0.56 \\
\hline Female & 47 & $23.3 \%$ & 31 & $15.4 \%$ & & & \\
\hline \multicolumn{8}{|l|}{ Ehnicity } \\
\hline Other ethnic group & 12 & $5.9 \%$ & 5 & $2.5 \%$ & $0.15^{*}$ & 1 & 0.70 \\
\hline White & 116 & $57.4 \%$ & 69 & $34.2 \%$ & & & \\
\hline \multicolumn{8}{|l|}{ SMID } \\
\hline Least deprived area & 49 & $24.3 \%$ & 15 & $7.4 \%$ & $6.22^{*}$ & 1 & 0.01 \\
\hline More deprived area & 79 & $39.1 \%$ & 59 & $29.2 \%$ & & & \\
\hline \multicolumn{8}{|l|}{ Diagnosis } \\
\hline ICD10 Schizophrenia, schizotypal \& delusional & 62 & $30.7 \%$ & 43 & $21.3 \%$ & 2.97 & 2 & 0.23 \\
\hline ICD10 Mood [affective] disorders & 48 & $23.8 \%$ & 19 & $9.4 \%$ & & & \\
\hline ICD10 other diagnosis & 18 & $8.9 \%$ & 12 & $5.9 \%$ & & & \\
\hline \multicolumn{8}{|l|}{ Marital Status } \\
\hline Married / defacto & 24 & $12.2 \%$ & 9 & $4.6 \%$ & $0.95^{*}$ & 1 & 0.33 \\
\hline Single & 101 & $51.5 \%$ & 62 & $31.6 \%$ & & & \\
\hline \multicolumn{8}{|l|}{ Living Situation } \\
\hline With others & 64 & $32.3 \%$ & 33 & $16.7 \%$ & $0.27^{*}$ & 1 & 0.60 \\
\hline Alone & 62 & $31.3 \%$ & 39 & $19.7 \%$ & & & \\
\hline \multicolumn{8}{|l|}{ Educational Attainment } \\
\hline School \& Further Education Quals & 119 & $59.5 \%$ & 63 & $31.5 \%$ & $3.86^{*}$ & 1 & 0.05 \\
\hline Did Not Attain School Quals & 7 & $3.5 \%$ & 11 & $5.5 \%$ & & & \\
\hline \multicolumn{8}{|l|}{ PREVIOUS EMPLOYMENT } \\
\hline Previous employment & 117 & $57.9 \%$ & 65 & $32.2 \%$ & $0.33^{*}$ & 1 & 0.57 \\
\hline No previous experience & 11 & $5.5 \%$ & 9 & $4.5 \%$ & & & \\
\hline
\end{tabular}

* indicates that the Pearson's has been calculated with Yates correction 
Table 6 Psychosocial variables Bivariate analysis

\begin{tabular}{|c|c|c|c|c|c|c|c|}
\hline \multirow[t]{2}{*}{ Characteristic } & \multicolumn{2}{|c|}{ Attained employment/education } & \multicolumn{2}{|c|}{ Did not attain employment/education } & \multicolumn{3}{|c|}{ Pearson's Chi-square test. ( ${ }^{*}$ with Yates Correction) } \\
\hline & $\mathrm{n}$ & $\%$ & $\mathrm{n}$ & $\%$ & $x^{2}$ & $d f$ & $p$ \\
\hline \multicolumn{8}{|c|}{ Assesses abilities and limitations } \\
\hline Supports & 93 & $46.3 \%$ & 44 & $21.9 \%$ & $3.47^{*}$ & 1 & 0.06 \\
\hline Interferes & 34 & $16.9 \%$ & 30 & $14.9 \%$ & & & \\
\hline \multicolumn{8}{|c|}{ Expectation of success in work (ExpSuc) } \\
\hline Supports & 73 & $36.1 \%$ & 36 & $17.8 \%$ & $1.01^{*}$ & 1 & 0.31 \\
\hline Interferes & 55 & $27.2 \%$ & 38 & $18.81 \%$ & & & \\
\hline \multicolumn{8}{|c|}{ Takes responsibility (Resp) } \\
\hline Supports & 80 & $39.6 \%$ & 31 & $15.4 \%$ & $7.23^{*}$ & 1 & 0.01 \\
\hline Interferes & 48 & $23.8 \%$ & 43 & $21.3 \%$ & & & \\
\hline \multicolumn{8}{|c|}{ Commitment to work (Commit) } \\
\hline Supports & 117 & $57.9 \%$ & 58 & $28.7 \%$ & $5.79 *$ & 1 & 0.02 \\
\hline Interferes & 11 & $5.5 \%$ & 16 & $7.9 \%$ & & & \\
\hline \multicolumn{8}{|c|}{ Work related goals (Goal) } \\
\hline Supports & 86 & $42.8 \%$ & 32 & $15.7 \%$ & $10.56^{*}$ & 1 & 0.001 \\
\hline Interferes & 41 & $20.4 \%$ & 42 & $20.9 \%$ & & & \\
\hline \multicolumn{8}{|c|}{ Enjoys work (Enjoy) } \\
\hline Supports & 94 & $47.7 \%$ & 56 & $28.4 \%$ & $0.00^{*}$ & 1 & 1.00 \\
\hline Interferes & 30 & $15.2 \%$ & 17 & $8.6 \%$ & & & \\
\hline \multicolumn{8}{|c|}{ Pursues interests (Interest) } \\
\hline Supports & 71 & $35.5 \%$ & 38 & $19.0 \%$ & $0.29^{*}$ & 1 & 0.59 \\
\hline Interferes & 55 & $27.5 \%$ & 36 & $18.0 \%$ & & & \\
\hline \multicolumn{8}{|c|}{ Appraises work expectations } \\
\hline Supports & 107 & $54.0 \%$ & 51 & $25.8 \%$ & $6.14^{*}$ & 1 & 0.01 \\
\hline Interferes & 18 & $9.1 \%$ & 22 & $11.1 \%$ & & & \\
\hline \multicolumn{8}{|c|}{ Influence of other roles } \\
\hline Supports & 97 & $48.0 \%$ & 49 & $24.3 \%$ & $1.69^{*}$ & 1 & 0.19 \\
\hline Interferes & 31 & $15.4 \%$ & 25 & $12.4 \%$ & & & \\
\hline \multicolumn{8}{|l|}{ Work habits } \\
\hline Supports & 92 & $46.7 \%$ & 37 & $18.8 \%$ & $7.88^{*}$ & 1 & 0.01 \\
\hline Interferes & 34 & $17.3 \%$ & 34 & $17.3 \%$ & & & \\
\hline \multicolumn{8}{|l|}{ Daily routines } \\
\hline Supports & 57 & $28.4 \%$ & 18 & $9.0 \%$ & $7.02 *$ & 1 & 0.01 \\
\hline Interferes & 71 & $35.3 \%$ & 55 & $27.4 \%$ & & & \\
\hline \multicolumn{8}{|c|}{ Adapts routines to minimize difficulties } \\
\hline Supports & 78 & $38.8 \%$ & 22 & $11.0 \%$ & $16.43^{*}$ & 1 & 0.0001 \\
\hline Interferes & 50 & $24.9 \%$ & 51 & $25.4 \%$ & & & \\
\hline \multicolumn{8}{|c|}{ Perception of physical work setting } \\
\hline Supports & 87 & $47.8 \%$ & 47 & $25.8 \%$ & $0.00^{*}$ & 1 & 0.97 \\
\hline Interferes & 32 & $17.6 \%$ & 16 & $8.8 \%$ & & & \\
\hline \multicolumn{8}{|c|}{ Perception of family and peers } \\
\hline Supports & 98 & $52.7 \%$ & 44 & $23.7 \%$ & $1.72^{*}$ & 1 & 0.19 \\
\hline Interferes & 25 & $13.4 \%$ & 19 & $10.2 \%$ & & & \\
\hline
\end{tabular}


Table 6 Psychosocial variables Bivariate analysis (Continued)

\begin{tabular}{|c|c|c|c|c|c|c|c|}
\hline \multirow[t]{2}{*}{ Characteristic } & \multicolumn{2}{|c|}{ Attained employment/education } & \multicolumn{2}{|c|}{ Did not attain employment/education } & \multicolumn{3}{|c|}{ Pearson's Chi-square test. ( ${ }^{*}$ with Yates Correction) } \\
\hline & $\mathrm{n}$ & $\%$ & $\mathrm{n}$ & $\%$ & $\overline{x^{2}}$ & $d f$ & $p$ \\
\hline \multicolumn{8}{|c|}{ Perception of boss and/or company } \\
\hline Supports & 49 & $34.0 \%$ & 29 & $20.1 \%$ & $0.01^{*}$ & 1 & 0.91 \\
\hline Interferes & 43 & $29.9 \%$ & 23 & $16.0 \%$ & & & \\
\hline \multicolumn{8}{|c|}{ Perception of co-workers } \\
\hline Supports & 59 & $43.1 \%$ & 30 & $21.9 \%$ & $0.00^{*}$ & 1 & 1.00 \\
\hline Interferes & 32 & $23.4 \%$ & 16 & $11.7 \%$ & & & \\
\hline
\end{tabular}

* indicates that the Pearson's has been calculated with Yates correction

regression models were built iteratively with nonsignificant variables removed at each step and the resulting nested model compared with the fuller model to assess significant difference in fit, three statistically significant variables are included in the final model: Adapting Routines to Minimise Difficulties, Work Related Goals, and Living in an Area of Lesser Deprivation. The variable Age has borderline significance within the model. Independence of errors was confirmed: DWT statistic $=1.93 p>0.05$. Multicollinearity was excluded, average $\mathrm{VIF}=1.2$ with a range from $0.74-1.35$; outliers were identified, three cases (1\%) were identified as outliers to the final model. A Cook's influence level of only 0.03 in all cases demonstrated the outliers have little influence over the final model. Therefore these cases were included. The final model is presented in Table 7. A rating of 'supports' in either Adapting Routines to Minimise Difficulties, or Work Related Goals will increase the odds of obtaining employment or educational. A 'supports' rating in Adapting Routines to Minimise Difficulties increases the likelihood of goal attainment by $261 \%$. A 'supports' score on Work related Goal increase the likelihood of obtaining employment or education by $143 \%$. Living in a Less Deprived Area improves the odds of attaining employment or education by $166 \%$. Age while not reaching levels of statistical significance within the model $(p<0.1)$ a younger age increases the likelihood of a successful outcome.

The datasets analysed during the current study are available in the clinical trials repository (NCT04083404).

\section{Discussion}

This study investigated an enhanced IPS service for people with SMI who are unemployed and seeking employment or education and explored if theoretically derived psychosocial variables can predict employment or education outcomes in this population.

\section{Outcomes of enhanced IPS}

Participants in this enhanced IPS programme had a $63 \%$ successful attainment of employment or education, which compares favourably to other UK non-experimental studies of standard IPS. An early study comparing standard IPS with traditional vocational rehabilitation (TVR) reported $56 \%$ of participants in standard IPS attained employment or education compared to $22 \%$ in TVR [59]. The same authors conducted a further study investigating standard IPS for young people with first episode psychosis [60] . Over an 18 month period the employment or education rates improved by $43 \%$ (baseline $=38 \%$; $18 \mathrm{mths}=81$ ). A later study focused on early intervention services, which included a 12 month trial of standard IPS, found

Table 7 Model of attainment of employment or education for enhanced IPS

\begin{tabular}{|c|c|c|c|c|}
\hline & \multirow[t]{2}{*}{$b(S E)$} & \multicolumn{3}{|c|}{ 95\% Cl for Odds Ratio } \\
\hline & & Lower & Odds Ratio & Upper \\
\hline Constant & $-0.03(0.72)$ & 0.23 & 0.96 & 3.91 \\
\hline Adapts Routines to Minimize Difficulties & $1.28(0.39) * * *$ & 1.72 & 3.61 & 7.86 \\
\hline Work-Related Goals & $0.89(0.36)^{*}$ & 1.21 & 2.43 & 4.99 \\
\hline Appraises Abilities and Limitations & $0.37(0.42)$ & 0.63 & 1.45 & 3.34 \\
\hline Work Routines & $0.06(0.41)$ & 0.47 & 1.07 & 2.38 \\
\hline Responsibility & $0.09(0.39)$ & 0.51 & 1.09 & 2.33 \\
\hline Age & $-0.03(0.02)$ & 0.94 & 0.97 & 1.00 \\
\hline Living in Least Deprived Area & $-0.98(0.39) *$ & 1.25 & 2.65 & 5.90 \\
\hline
\end{tabular}

$R^{2}=0.16$ (Hosmer-Lemeshow), 0.19(Cox-Snell), 0.26 (Nagelkerke)

Model ${ }^{2}(7)=41.38 p<.001$

${ }^{*} p<0.05{ }^{* * *} p<0.001$ 
employment/education attainment improved by $23 \%$ (baseline rate $=23 \% ; 12 \mathrm{mth}$ rate $=35 \%$ ) [61]. It could, therefore, be concluded that the enhanced IPS program in the present study, with a success rate of $63 \%$. Caution should be exercised in comparing this present study to the $55 \%$ success rate of international randomised controlled trials [5], due to the different research designs used. In addition, the UK randomised control trials (RCT) of standard IPS outcomes are 46\% [62] and 22\% [63]. Previous research has offered an explanation for the lower UK outcomes compared with US studies are differences in employment protection legislation availability of welfare/ disability benefits $[64,65]$.

Results of this present study should also be considered in the context of other studies investigating enhancements of IPS. To date the only other adaptation to standard IPS studied in the UK is the IPS-Lite [62], establishing that a time-limited (up to 9 months) implementation of IPS-Lite yielded a success rate of $41 \%$ compared to standard IPS employment rate of $46 \%$. The authors argue that the time limit increased capacity of IPS services and focuses efforts on those most likely to benefit. The present study compliments IPS Lite by offering an enhanced IPS to support those unable to attain employment within the IPS-Lite defined 9 months, particularly those who require a more complex intervention than standard IPS. Meta-analytic study of international RCTs found enhanced IPS was more effective than supported employment (RR 1.40, 95\% CI 0.92 to 2.14) [9]. Individual placement and support enhanced with social skills training [66], found $82.8 \%$ of participants in the enhanced IPS attained employment compared to $61.5 \%$ of standard IPS participants. However, authors acknowledge that the study sample is small and those with more severe symptoms were excluded. A study of IPS enhancement through cognitive remediation [67] identified enhanced IPS (69.6\%) over standard IPS (14.3\%), but, low adherence to IPS fidelity was reported in both arms of the study, which may explain the poor standard IPS outcome. Moreover, another study investigating enhancement through cognitive remediation reported enhanced IPS yielding 15.2\% employment outcomes and $14.9 \%$ for standard IPS [14]. It could be concluded that alternative enhancements are still in development and reliable research findings not yet established. The present study offers an additional enhanced IPS program not currently being studied within the field.

\section{Psychosocial variables predict outcomes}

Previous studies have argued that future research should investigate psychosocial variables which may predict success [17]. Our study found seven psychosocial items from the intake assessment were significantly correlated with outcome $(p<0.01)$, and two of these items (Adapts
Routines to Minimise Difficulties and Work Related Goals) contribute to a multiple regression model. It could, therefore, be argued that an assessment (e.g., WRI) of psychosocial factors at commencement of an enhanced IPS intervention would be valuable. Developers of IPS recommend that vocational assessments are not required in IPS programmes [68], although do encourage information gathering through the career profile interview. Reservations regarding assessments seem to be primarily founded on the perception that vocational evaluation is limited to performance capacity measurement, and will lead to the screening out of individuals with limitations [68]. This study has provided evidence of the value of the Worker Role Interview which identifies psychosocial strengths which may be built upon. Clinicians assessing psychosocial strengths, using the WRI, at the beginning of an enhanced IPS intervention would allow appropriate targeting of enhanced IPS interventions, thus improving efficiencies [11, 17].

Previous research has also found work related goals expressed as a desire to work $[29,30]$ is predictive of positive employment outcome. Work Habits and Routines are also emerging as promising predictors of employment or educational outcomes. Work Routines was also significant in a study predicting return to work from sickness absence [38] at both univariate level and within multivariate regression. Adapts Routines to Minimize Difficulties was also significant at univariate level in return to work from sickness absence study [38] and has also been found to differentiate between employed and unemployed US veterans [69]. Work Habits, while significant in the present study, has not been found to be significant in any other study predicting employment outcomes. Perception of Family and Peers, was not found to be significant, however, was considered a clinically important factor by therapists in this present study. Non significance maybe due to missing data (8\%) [55], resulting from the difficulty rating the variable. Additionally, therapists involved in this present study concurred with other authors $[34,70,71]$ that the environmental factors are clinically important. The final multiple logistic regression model included Adapts Routines to Minimize Difficulties and Work-related Goals. Significant finding of Work-related Goals has resonance with previous research $[29,30]$ and a rating of "supports" requires the individual to not only express a desire for employment but for this to be demonstrated in behaviour "setting realistic goals and setting clear plans for finding work" [46]. Similarly the Adapts Routines to Minimize Difficulties item is behavioural in nature and is defined as "how the person has managed use of time, routine, and habits since the injury or since being out of work" [46]. Together these items offer measurable rating of the enactment of desire for employment. The present study 
relied upon routine collected clinical data and therefore only captured attainment of employment or education. It is recommended that future studies should investigate if psychosocial variables predict retention of employment and education by including greater detail on the type of work or educational programme secured and the duration.

\section{Population served}

This present study was focused on a population who are unemployed and often have minimal or distant employment experience. While four items overlapped by being significant across sickness absence population and a prolonged absence from employment population at univariate level (Adapts Routines; Daily Routines; Takes Responsibility and Commitment to Work), the multiple regression model identified different items as being significant in each population. This difference perhaps reflects how psychosocial variables vary depending on people having an employment experience to reflect upon and how daily routines change to reflect a short period of absence compared to a complete non-existence of worker role. Therapists described difficulty rating some of the WRI items due to the absence of recent employment experience to reflect upon and this resulted in missing data. This was particularly evident in all four environmental items. Similar challenges were acknowledged in a previous study [50]. Therefore practitioners need to be creative in considering interventions which allow clients to have a real work experience prior to rating the WRI in populations who have been out of work for a longer time period.

\section{Limitations}

The demographic profile of this present study is similar to other IPS studies $[63,72-76]$ in that it does not represent the SMI population. The present study had a high rate of those in marital/equivalent relationships; more males than females and very few younger people. While it is recognised that young people should have early access to IPS programmes it is notable that the mean age of many IPS RCTs is over 35 yrs. [63, 72-76]. Age was a significant variable at univariate analysis in this present study but was not significant in the multiple regression model. Better representation of young people in this sample would perhaps have increased significance. This study had an unusually high (90\%) previous employment rate. A history of employment is recognised as predicting success $[35,77]$. However, recency is relevant to the predictive nature of employment history [19, 78]. Studies in the field usually define this variable as a reported work history in the last 3-5 years. The high percentage of employment history identified in this study is perhaps explained by the over-inclusive definition of previous employment being any work including from teenage life, which does not attend to the recency of employment. Therefore comparisons between this present study and others is not possible. In the present study $17 \%$ of the sample were married or de facto relationship, while in UK population study only $0.5 \%$ of those with a psychotic illness were in a similar relationship [79]. In this study $51 \%$ were living alone, compared with a national average for people with SMI of 35\% [80]. The sample was also predominately well educated, with $60 \%$ having pursued education beyond school level, had a low ethnic diversity and a third (32\%) of the sample lived in an area classified as in least deprived. Future studies need to be clear about the population who received the IPS service to allow for a clearer understand of which subset of the SMI population is being served. It is possible that the patients excluded from the study may have skewed data however more than half of those excluded were not appropriate participants in an IPS programme not having an employment goal, being in employment or refusing to intervention. Withdrawal from intervention is also a widely recognised challenge in this population [81].

\section{Conclusion}

The study adds to the evidence base of vocational rehabilitation introducing a new enhanced IPS intervention based on the $\mathrm{MOHO}$ which achieved $63 \%$ return to employment or education and can provide alternatives to standard IPS and IPS-Lite for people who have more complex needs. This study also extends knowledge regarding the relevance of the WRI with an SMI population. Motivational and habitual psychosocial variables are identified as helpful in predicting who may benefit from an enhanced IPS intervention after prolonged absence of previous employment. This study also provides an example of embedding research into core health services promoting sustainability. The challenge of sustainability is a factor to consider in RCT research, where well-funded and managed trials are successful for the duration of implementation but are not integrated into mainstream services [82-84].

\footnotetext{
Abbreviations

Cl: Confidence Interval; DWT: Durbin-Watson Test; ICD10: International Classification of Diseases, Tenth Revision; IPS: Individual placement and support; IQ: Interquartile; IRAS: Integrated Research Application System; $\mathrm{MOHO}$ : Model of human occupation; $\mathrm{R}^{2}$ : Coefficient of determination; $\mathrm{RCT}$ : Randomised control trials; SD: Standard deviation; SIMD: Scottish Indices of Multiple Deprivation; SMI: Severe mental illness; UK: United Kingdom; US: United States of America; VIF: Variance Inflation Factor; WRI: Work Role Interview
}

Acknowledgements

We thank the therapists at the vocational rehabilitation service who collected data and participated in the clinical consultation. We also thank Dr. Anusua Singh Roy, statistician for her advice on data analysis. 


\section{Authors' contributions}

SP DM RWA BK AL LVN LIF and KF made substantial contributions to the conception of the study. SP DM LIF and KF contributed to the design of the work. SP DM LIF and KF were responsible for the acquisition, analysis and interpretation of data. SP and KF drafted the manuscript. SP DM RWA BK AL LVN LIF and KF were involved in critical revision of manuscript, all authors read and approved the manuscript submitted.

\section{Funding}

This study was funded by the Scottish Government. The funding body had no role in the design of the study and collection, analysis, and interpretation of data and in writing the manuscript.

\section{Availability of data and materials}

The datasets analysed during the current study are available in the clinical trials repository (NCT04083404).

\section{Ethics approval and consent to participate}

The study was reviewed and approved by the proportionate review subcommittee of the South Central - Berkshire B Research Ethics Committee (IRAS ID 230949) and has, therefore, been performed in accordance with the ethical standards laid down in the 1964 Declaration of Helsinki and its later amendments. The study is a secondary analysis of anonymised data collected for clinical purposes. Procedures for anonymisation and transfer of data were detailed in the ethical application.

\section{Consent for publication}

Not applicable.

\section{Competing interests}

The authors declare that they have no competing interests.

\section{Author details}

'Queen Margaret University, Edinburgh EH21 6UU, UK. ${ }^{2}$ Faculty of Health Sciences, University of Stavanger \& Oslo Metropolitan University, Oslo, Norway. ${ }^{3}$ Department of Occupational Science and Occupational Therapy, University of Toronto, Toronto, Canada. ${ }^{4}$ Department of Health Sciences/ Mental Health Activity and Participation (MAP), Lund University, Lund, Sweden. ${ }^{5}$ Division of Occupational Therapy, University Stellenbosch, Stellenbosch, South Africa. ${ }^{6}$ Mental Health and Wellbeing, City of Edinburgh Health and Social Care Partnership, Waverley Court, Edinburgh EH8 8BG, UK.

Received: 26 September 2019 Accepted: 19 June 2020

\section{Published online: 08 July 2020}

\section{References}

1. United Nations General Assembly. Universal declaration of human rights. 1948.

2. Mueser KT, Cook JA. Why can't we fund supported employment? Psychiatr Rehabil J. 2016;39:85-9.

3. Marwaha S, Johnson S, Bebbington P, Stafford M, Angermeyer MC, Brugha $T$, et al. Rates and correlates of employment in people with schizophrenia in the UK, France and Germany. Br J Psychiatry. 2018;191:30-7.

4. Waghorn GR, Chant DC, Lloyd C, Harris MG. Labour market conditions, labour force activity and prevalence of psychiatric disorders. Soc Psychiatry Psychiatr Epidemiol. 2009:44:171-8

5. Bond GR. Evidence for the Effectiveness of Individual Placement and Support Model of Supported Employment. Washington, DC: American Psychiatric Association; 2019. Available from: https://ipsworks.org/index.php/ evidence-for-ips/. [cited 2019 Aug 1].

6. Modini M, Tan L, Brinchmann B, Wang M-J, Killackey EJ, Glozier N, et al. Supported employment for people with severe mental illness: systematic review and meta-analysis of the international evidence. Br J Psychiatry. 2016;209:14-22.

7. Frederick DE, VanderWeele TJ. Supported employment: Meta-analysis and review of randomized controlled trials of individual placement and support. Pompili M, editor. PLoS ONE. 2019;14:e0212208.

8. Kinoshita Y, Furukawa TA, Kinoshita K, Honyashiki M, Omori IM, Marshall M, et al. Supported employment for adults with severe mental illness. Cochrane Database Syst Rev. 2013;13(9):CD008297.
9. Suijkerbuijk YB, Schaafsma FG, van Mechelen JC, Ojajärvi A, Corbière M, Anema JR. Interventions for obtaining and maintaining employment in adults with severe mental illness, a network meta-analysis. Cochrane Database Syst Rev. 2017;12:297.

10. Au DWH, Tsang HW-H, So WWY, Bell MD, Cheung V, Yiu MGC, et al. Effects of integrated supported employment plus cognitive remediation training for people with schizophrenia and schizoaffective disorders. Schizophr Res. 2015;166:297-303 Elsevier.

11. Dewa CS, Loong D, Trojanowski L, Bonato S. The effectiveness of augmented versus standard individual placement and support programs in terms of employment: a systematic literature review. J Ment Health. 2018;27: 174-83.

12. Bell MD, Choi K-H, Dyer C, Wexler BE. Benefits of cognitive remediation and supported employment for schizophrenia patients with poor community functioning. Psychiatr Serv. 2014;65:469-75.

13. McGurk SR, Mueser KT, Xie H, Welsh J, Kaiser S, Drake R, et al. Cognitive enhancement treatment for people with mental illness who do not respond to supported employment: A randomized controlled trial. Am J of Psychiat. American Psychiatric AssociationArlington, VA. 2015:172:852-L.

14. Sato S, Iwata K, Furukawa S-I, Matsuda Y, Hatsuse N, Ikebuchi E. The effects of the combination of cognitive training and supported employment on improving clinical and working outcomes for people with schizophrenia in Japan. CP EMH. 2014;10:18-27.

15. Tsang HW-H, Leung AY, Chung RCK, Bell MD, Cheung W. Review on vocational predictors: a systematic review of predictors of vocational outcomes among individuals with schizophrenia: an update since 1998. Aust NZ J Psychiatry. 2010;44:495-504.

16. Noyes S, Sokolow H, Arbesman M. Evidence for occupational therapy intervention with employment and education for adults with serious mental illness: A systematic review. Am J Occup Ther. 2018;72: $7205190010 p 1$.

17. Metcalfe JD, Riley J, McGurk SR, Hale T, Drake R, Bond GR. Comparing predictors of employment in individual placement and support: a longitudinal analysis. Psychiatry Res. 2018;264:85-90.

18. Campbell K, Bond GR, Drake R, McHugo GJ, Xie H. Client predictors of employment outcomes in high-fidelity supported employment. J Nerv Ment Dis. 2010;198:556-63.

19. Corbière $M$, Zaniboni $S$, Lecomte $T$, Bond GR, Gilles P-Y, Lesage $A$, et al. Job acquisition for people with severe mental illness enrolled in supported employment programs: a theoretically grounded empirical study. J Occup Rehabil. 2011:21:342-54.

20. Austin $\mathrm{BS}$, Lee $\mathrm{CL}$. A structural equation model of vocational rehabilitation services: predictors of employment outcomes for clients with intellectual and co-occurring psychiatric disabilities. J Rehabil. 2014;80:11-20.

21. Mueser KT, Salyers MP, Mueser PR. A prospective analysis of work in schizophrenia. Schizophr Bull. 2001;27:281-96.

22. Salkever DS, Karakus MC, Slade EP, Harding CM, Hough RL, Rosenheck RA, et al. Measures and predictors of community-based employment and earnings of persons with schizophrenia in a multisite study. Psychiatr Serv. 2007:58:315-24.

23. Rosenheck RA, Leslie D, Keefe R, McEvoy J, Swartz M, Perkins D, et al. Barriers to employment for people with schizophrenia. Am J of Psychiat. 2006:163:411-7.

24. Marwaha S, Johnson S, Bebbington PE, Angermeyer MC, Brugha TS, Azorin J$\mathrm{M}$, et al. Predictors of employment status change over 2 years in people with schizophrenia living in Europe. Epidemiol Psychiatr Soc. 2009;18:344-51.

25. Brouwer S, Reneman MF, Bültmann U, Klink JJL, Groothoff JW. A prospective study of return to work across health conditions: perceived work attitude, selfefficacy and perceived social support. J Occup Rehabil. 2010;20:104-1129p.

26. Holmgren K, Ekbladh E, Hensing G, Dellve L. The combination of work organizational climate and individual work commitment predicts return to work in women but not in men. J Occup Environ Med. 2013:55:121-7.

27. Ekbladh E, Sandqvist JL. Psychosocial factors' influence on work ability of people experiencing sick leave resulting from common mental disorders. Occup Ther Ment Health. 2015;31:283-97.

28. Shames J, Treger I, Ring H, Giaquinto S. Return to work following traumatic brain injury: trends and challenges. Disabil Rehabil. 2009;29:1387-95.

29. Kirsh $\mathrm{BH}$. Factors associated with employment for mental health consumers. Psychiatr Rehabil J. 2000;24:13-219p.

30. Campbell K, Bond GR, Drake R. Who benefits from supported employment: a meta-analytic study. Schizophr Bull. 2011;37:370-80. 
31. Ekbladh E, Thorell L-H, Haglund L. Perceptions of the work environment among people with experience of long term sick leave. Work. 2010;35:125$13612 \mathrm{p}$.

32. Evensen S, Ueland T, Lystad JU, Bull H, Klungsøyr O, Martinsen EW, et al. Employment outcome and predictors of competitive employment at 2-year follow-up of a vocational rehabilitation programme for individuals with schizophrenia in a high-income welfare society. Nord J Psychiatry. 2016;71:180-7.

33. Burke-Miller JK, Razzano LA, Grey DD, Blyler CR, Cook JA. Supported employment outcomes for transition age youth and young adults. Psychiatr Rehabil J. 2012;35:171-9.

34. Kirsh BH. Client, contextual and program elements influencing supported employment: a literature review. Community Ment Health J. 2016;52:809-20.

35. Catty J, Lissouba P, White $\mathrm{S}$, Becker T, Drake R, Fioritti A, et al. Predictors of employment for people with severe mental illness: results of an international six-Centre randomised controlled trial. Br J Psychiatry. 2008; 192:224-31.

36. Taylor RR. In: Taylor RR, editor. Kielhofner's model of human occupation. 5th ed. Philadelphia: Lippincott Williams \& Wilkins; 2017.

37. Wästberg BA, Haglund L, Eklund M. Psychometric properties of the worker role self-assessment instrument used to evaluate unemployed people in Sweden. Scand J Occup Ther. 2009;16:238-46.

38. Ekbladh E, Thorell L-H, Haglund L. Return to work: the predictive value of the worker role interview (WRI) over two years. Work. 2010;35:163-72.

39. Delespaul $\mathrm{PH}$, de consensusgroep EPA. Consensus regarding the definition of persons with severe mental illness and the number of such persons in the Netherlands. Tijdschr Psychiatr. 2013;55:427-38.

40. Martínez-Martínez C, Richart-Martínez M, Ramos-Pichardo JD. Operational definition of serious mental illness: heterogeneity in a review of the research on quality-of-life interventions. J Am Psychiatr Nurses Assoc. 2020; 55:107839032090282

41. Siriwardena AN. Experimental methods in health research. In: Saks M, Allsop J, editors. Researching Health. Thousand Oaks: SAGE Publication; 2012. p. 263-79

42. Smith AK, Ayanian JZ, Covinsky KE, Landon BE, McCarthy EP, Wee CC, et al. Conducting high-value secondary dataset analysis: an introductory guide and resources. J Gen Intern Med. 2011:26:920-9.

43. Bond GR, Becker D, Drake R. Measurement of fidelity of implementation of evidence-based practices: case example of the IPS fidelity scale. Clin Psychol. 2011;18:126-41.

44. Doolan DM, Froelicher ES. Using an existing data set to answer new research questions: a methodological review. Res Theory Nurs Pract. 2009; 23:203-15.

45. Cheng HG, Phillips MR. Secondary analysis of existing data: opportunities and implementation. Shanghai Arch Psychiatry. 2014;26:371-5.

46. Braveman B, Robson M, Velozo CA, Kielhofner G, Fisher GS, Forsyth K, et al. Worker role interview (WRI) (version 10.0). Chicago: Model of Human Occupation Clearinghouse, Department of Occupational Therapy, College of Applied Health Sciences, University of Illinois at Chicago; 2005.

47. Forsyth K, Braveman B, Kielhofner G, Ekbladh E, Haglund L, Fenger K, et al. Psychometric properties of the worker role interview. Work. 2006;27:313-8.

48. Fenger $\mathrm{K}, \mathrm{Kramer} \mathrm{JM}$. Worker role interview: testing the psychometric properties of the Icelandic version. Scand J Occup Ther. 2007;14:160-72.

49. Köller B, Niedermann K, Klipstein A, Haugboelle J. The psychometric properties of the German version of the new worker role interview (WRI-G 10.0) in people with musculoskeletal disorders. Work. 2011:40:401-10.

50. Lohss I, Forsyth K, Kottorp A. Psychometric Properties of the Worker Role Interview (Version 10.0) in Mental Health. Br J Occup Ther. 2012;75:171-9.

51. Peduzzi P, Concato J, Kemper E, Holford TR, Feinstein AR. A simulation study of the number of events per variable in logistic regression analysis. J Clin Epidemiol. 1996;49:1373-9.

52. R Core Team. R. A language and environment for statistical computing (software version 3.2.2) [online]. Vienna: R Foundation for Statistical Computing; 2015.

53. Stoltzfus JC. Logistic Regression: a brief primer. Acad Emerg Med. 2011;18: 1099-104 Blackwell Publishing Ltd.

54. Hosmer DW Jr, Lemeshow S, Sturdivant RX. Applied Logistic Regression. 3rd ed. Hoboken: Wiley; 2013. p. 1-510.

55. Field A. Logistic Regression. Discovering Statistics Using R. Thousand Oaks: Sage Publications, Incorporated; 2012. p. 312-59.

56. Regression FA. Discovering statistics using R. Thousand Oaks: Sage Publications, Incorporated; 2012. p. 245-311.
57. World Health Organization. The ICD-10 Classification of Mental and Behavioural Disorders. 10th ed. Geneva: World Health Organization; 2016.

58. Field A, Miles J, Zow F. Discovering statistics using R. London: Sage Publications, Incorporated; 2012.

59. Rinaldi M, Perkins R. Comparing employment outcomes for two vocational services: individual placement and support and non-integrated prevocational services in the UK. J Vocat Rehabil. 2007;27:21-7.

60. Rinaldi M, Miller L, Perkins R. Implementing the individual placement and support (IPS) approach for people with mental health conditions in England. Int Rev Psychiatry. 2010;22:163-72.

61. Dudley R, Nicholson M, Stott P, Spoors G. Improving vocational outcomes of service users in an early intervention in psychosis service. Early Interv Psychia. 2014;8:98-102.

62. Burns T, Yeeles K, Langford O, Montes MV, Burgess J, Anderson C. A randomised controlled trial of time-limited individual placement and support: IPS-LITE trial. Br J Psychiatry. 2015;207:351-6.

63. Heslin M, Howard LM, Leese M, McCrone P, Rice C, Jarrett M, et al. Randomized controlled trial of supported employment in England: 2 year follow-up of the Supported Work and Needs (SWAN) study. World Psychiatry. 2011;10:132-7.

64. Burns T, Catty J, Becker T, Drake R, Fioritti A, Knapp M, et al. The effectiveness of supported employment for people with severe mental illness: a randomised controlled trial. Lancet. 2007;370:1146-52.

65. Metcalfe JD, Drake R, Bond GR. Economic, labor, and regulatory moderators of the effect of individual placement and support among people with severe mental illness: a systematic review and meta-analysis. Schizophr Bull. 2018:44:22-31.

66. Tsang HW-H, Fung KMT, Leung AY, Li SMY, Cheung WM. Three year followup study of an integrated supported employment for individuals with severe mental illness. Aust N Z J Psychiatry. 2010;44:49-58.

67. McGurk SR, Mueser KT, Feldman K, Wolfe R, Pascaris A. Cognitive training for supported employment: 2-3 year outcomes of a randomized controlled trial. Am J of Psychiat. 2007;164:437-41.

68. Swanson SJ. Applying the individual placement and support (IPS) model to help clients compete in the workforce. Dartmouth: PRC-Hazelden; 2015.

69. Julian $\mathrm{CH}$, Valente JM. Psychosocial factors related to returning to work in $\mathrm{U}$. S. Army Soldiers. Albin TJ, editor. Work. 2015;52:419-31.

70. Argentzell E, Eklund M. Perceptions of the worker role among people with psychiatric disabilities: description and investigation of associated factors. Work. 2013:45:289-98.

71. Prior S, Maciver D, Forsyth K, Walsh M, Meiklejohn A, Irvine L. Readiness for employment: perceptions of mental health service users. Community Ment Health J. 2013:49:658-67.

72. Latimer EA, Lecomte T, Becker D, Drake R, Duclos I, Piat M, et al. Generalisability of the individual placement and support model of supported employment: results of a Canadian randomised controlled trial. Br J Psychiatry. 2006:189:65-73.

73. Bejerholm U, Areberg C, Hofgren C, Sandlund M, Rinaldi M. Individual placement and support in Sweden - a randomized controlled trial. Nord J Psychiatry. 2015;69:57-66.

74. Mueser KT, Clark RE, Haines M, Drake R, McHugo GJ, Bond GR, et al. The Hartford study of supported employment for persons with severe mental illness. J Consult Clin Psychol. 2004:72:479-90.

75. Oshima I, Sono T, Bond GR, Nishio M, Ito J. A randomized controlled trial of individual placement and support in Japan. Psychiatr Rehabil J. 2014;37: 137-43.

76. Bond GR, Salyers MP, Dincin J, Drake R, Becker D, Fraser W, et al. A randomized controlled trial comparing two vocational models for persons with severe mental illness. J Consult Clin Psychol. 2007;75:968-82.

77. Tsang HW-H, Lam P, Ng B, Leung O. Predictors of employment outcome for people with psychiatric disabilities: a review of the literature since the mid '80s. J Rehabil. 2000:66:19-3113p.

78. Corbière M, Lecomte T, Reinharz D, Kirsh BH, Goering P, Menear M, et al. Predictors of acquisition of competitive employment for people enrolled in supported employment programs. J Nerv Ment Dis. 2017;205(4):275-82.

79. McManus S, Meltzer $H_{1}$ Brugha TS, Bebbington PE, Jenkins R. Adult Psychiatric Morbidity in England, 2007: Results of a Household Survey. The NHS Information Centre for Health and Social Care (2009). Leeds: The NHS Information Centre for Health and Social Care. p. 2009.

80. Scottish Household Survey Project Team. Scottish household survey 2016: annual report. Edinburgh: Scottish Government; 2017 Jan. 
81. Fiszdon JM, Kurtz MM, Choi J, Bell MD, Martino S. Motivational interviewing to increase cognitive rehabilitation adherence in schizophrenia. Schizophr Bull. 2016;42:327-34.

82. Markström U, Svensson B, Bergmark M, Hansson L, Bejerholm U. What influences a sustainable implementation of evidence-based interventions in community mental health services? Development and pilot testing of a tool for mapping core components. J Ment Health. 2nd ed. Routledge. 2017;35:1-7.

83. Noel VA, Bond GR, Drake R, Becker D, McHugo GJ, Swanson SJ, et al. Barriers and facilitators to sustainment of an evidence-based supported employment program. Adm Policy Ment Health. 2017;44:331-8 Springer US.

84. Bergmark M, Bejerholm U, Markström U. Implementation of evidence-based interventions: analyzing critical components for sustainability in community mental health services. Social Work Mental Health. 2nd ed. 2018:35:1-20.

\section{Publisher's Note}

Springer Nature remains neutral with regard to jurisdictional claims in published maps and institutional affiliations.

Ready to submit your research? Choose BMC and benefit from:

- fast, convenient online submission

- thorough peer review by experienced researchers in your field

- rapid publication on acceptance

- support for research data, including large and complex data types

- gold Open Access which fosters wider collaboration and increased citations

- maximum visibility for your research: over $100 \mathrm{M}$ website views per year

At BMC, research is always in progress.

Learn more biomedcentral.com/submissions 